\title{
Short-term recognition memory for complex free-form figures
}

\author{
GREGORY W. CERMAK \\ Stanford University, Stanford, Calif. 94305
}

Evidence from an STM experiment is presented which suggests that visual information need not be recoded verbally. In a same-different recognition task in which stimuli were free-form nonsense figures, recognition rates were substantially above chance for memory intervals of up to $20 \mathrm{sec}$. The nature of the items to be remembered renders very unlikely an explanation of the data based on verbal coding of the visual information.

The notion of a short-term store (STS) occupies a central position in several important models of memory (see, for example, Atkinson \& Shiffrin, 1968; Norman, 1969). One of the most important aspects of STS is that the recoding of incoming information is associated with it. In studies of a possible STS and of recoding, typically the items to be remembered are verbal or easily verbalizable (e.g., alphanumeric characters, schematic drawings, easily labeled pictures) so that most available data either support the view that visually presented material is recoded and remembered in verbal or quasiverbal form or are noncommittal on the subject.

Of the few studies which do explore nonverbal coding of stimuli at retention intervals roughly between 1 and $30 \mathrm{sec}$ (e.g., Heider \& Olivier, in press; Kroll, Parks, Parkinson, Bieber, \& Johnson, 1970; Posner \& Konick, 1966), there appears to be just one which uses stimuli: (1) not easily coded verbally, $(2)$ in a recognition task, and (3) employing several retention intervals (Phillips \& Baddeley, 1971). In the Phillips and Baddeley study, retention intervals were $0.3,1,3$, and 9 sec. At 9-sec delay, recognition accuracy approached chance, so that, effectively, few positive data exist on short-term recognition memory at delays of greater than $3 \mathrm{sec}$, although "short-term" memory often is considered to extend to $30 \mathrm{sec}$ (e.g., Atkinson \& Shiffrin, 1968, p. 101), and perhaps beyond.

The present study was designed to test human Ss' ability to recognize figures that could not easily be coded verbally at several retention intervals greater than 3 sec so that a clearer picture of recognition performance throughout the "short-term" range might be obtained. More explicitly, the effect of increasing retention intervals on recognition performance can be examined for a possible asymptote and for any abrupt changes in performance which might indicate a coding strategy change.
Cermak (in press). These figures are novel and multidimensional, with the important properties that (a) individually they are not easily described verbally; (b) the pairwise differences of adjacent ${ }^{1}$ figures are slight and not easily described verbally; and (c) the differences between adjacent figures vary, depending on the particular pair of figures, so that no set of readily verbalized rules could characterize the differences between all pairs of adjacent figures. Thus, given one of the 81 figures, it would be quite difficult to construct a quick verbal description that would suffice to differentiate it from an (unknown) upcoming adjacent figure. Further, experiments suggest that magnitude of perceived difference between adjacent figures is relatively constant for all adjacent pairs. ${ }^{2}$ Properties $a, b$, and $c$ are illustrated in Fig. 1.

The stimuli were 81 free-form nonsense figures. A detailed account of the properties and production of these figures and further illustration of them are contained in Shepard \&
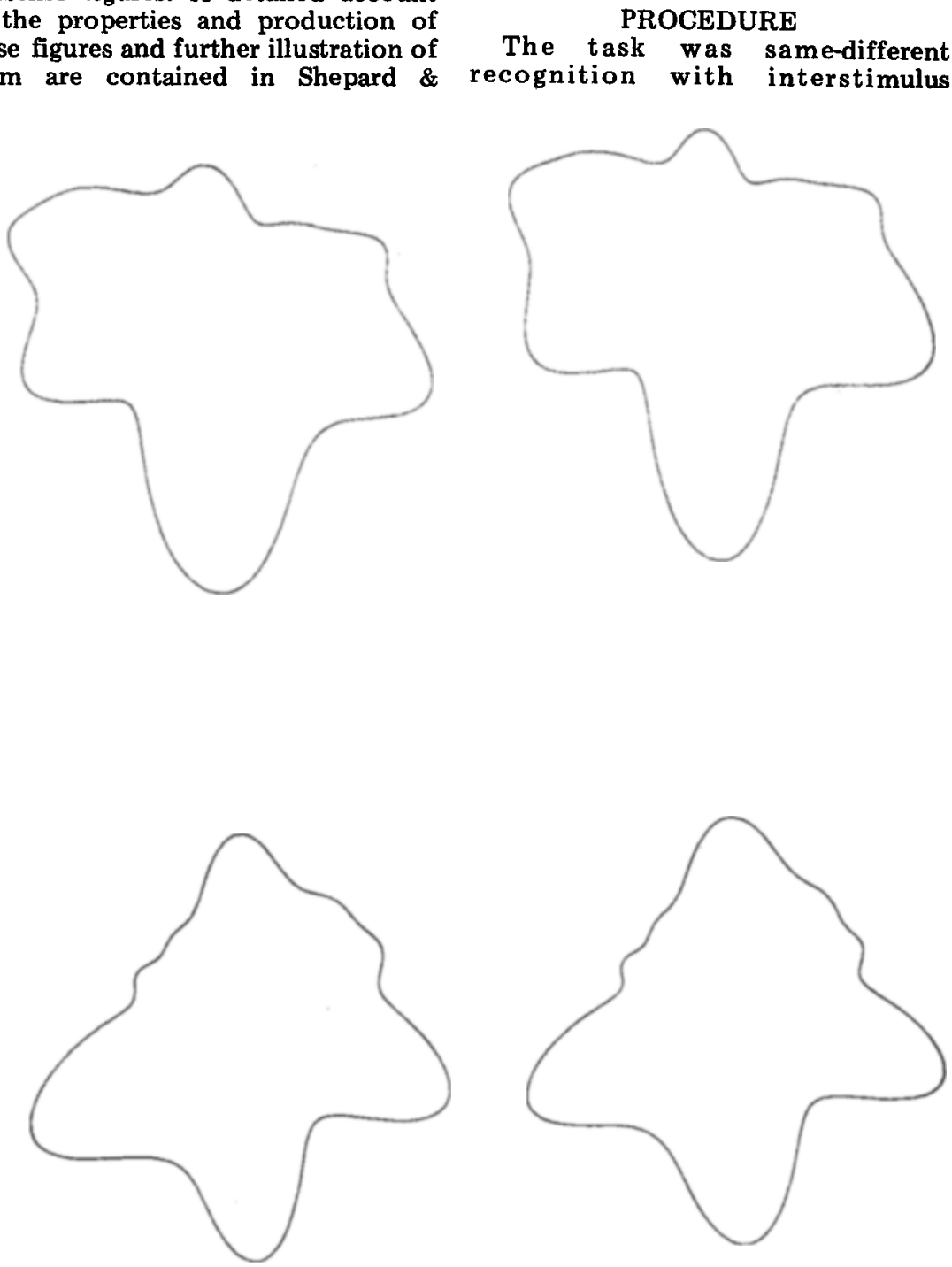

Fig. 1. Two pairs of parametrically adjacent figures from the set of 81 . The pairs are from different regions in the set's parameter space. 
intervals (ISI) of $1.5,4,12$, and $20 \mathrm{sec}$. The 81 figures were sampled so that for 27 target figures presented for study, the figure presented during test was a parametrically adjacent figure, and for 27 figures, the study and test figures were identical. Each of the 81 figures was thus presented in exactly one trial. Order of same and different pairs was randomized. Trials were blocked over ISI. All (24) possible orders of the four ISI blocks were constructed and randomly assigned to Ss so that each $S$ received a unique ordering of the four ISIs. The sequence of 54 pairs of figures was partitioned into four blocks also, and these blocks were arranged in the four orders obtained by a cyclic permutation so that each pair of figures appeared in each quarter of the presentation sequence for an equal number of Ss. Instructions stressed that the probability of the test figure being the same as the study figure was 0.5 and that the sequence of same and different pairs was random. Ss were not instructed to employ any particular study or rehearsal strategy. Ss were informed before each ISI block of the upcoming ISI. No feedback was provided during the experiment.

The figures were affixed to cards and presented in a three-field tachistoscope. Each figure subtended approximately $2 \mathrm{deg}$ of visual angle. The study figure appeared for $5 \mathrm{sec}$, followed by a white field for the duration of the ISI. Then the test figure appeared for $5 \mathrm{sec}$. $S$ responded verbally, with "same" and "different" being the only allowed responses.

RESULTS AND DISCUSSION

Recognition accuracy was substantially above chance for all ISIs. As shown in Fig. 2, mean proportion correct ranged from .78 for an ISI of $1.5 \mathrm{sec}$ to .66 for an ISI of $20 \mathrm{sec}$, with the overall mean proportion correct about .70 . The dashed line in Fig. 2 represents two standard deviations from chance, based on a null hypothesis of random guessing for each ISI and with probability of a correct guess being 0.5. Furthermore, proportions correct for same and different pairs were approximately equal (.69 and .72 , respectively), so that the overall recognition rate was not spuriously inflated by the stimuli within different pairs being so discrepant that the figures were easily discriminated. Also, for both same and different pairs, the frequency with which individual pairs were responded to correctly was distributed unimodally and roughly symmetrically, another indication that the recognition rate was not an artifact of having a few easily discriminated pairs of figures. Thus, the proportion

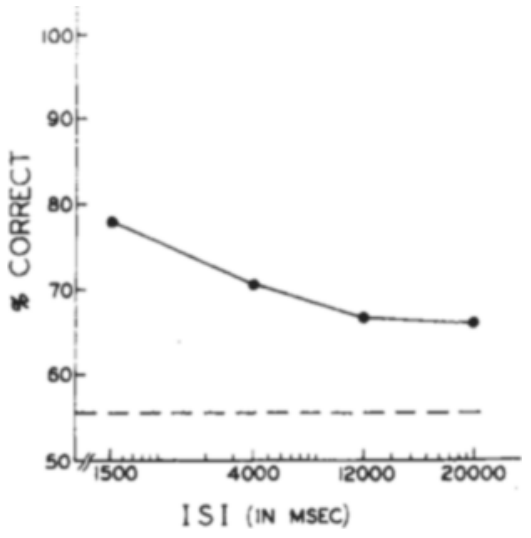

Fig. 2. Percent correct recognition as a function of ISI. The dashed line represents two standard deviations from chance, given random guessing.

correct data represent a substantial recognition rate for both same and different pairs.

As Fig. 2 indicates, recognition decreased for increasing ISI, seeming to reach an asymptote at about 20 sec. An analysis of variance performed on the standard arcsin transform of the data confirmed that ISI affected recognition performance $[F(3,80)=4.95, p<.01]$ and indicated no reliable effect of presentation block $[F(3,80)=1.11$, n.s.] or of ISI by Block interaction $[F(9,80)=1.88$, n.s. $]$. Most of the decrease in recognition accuracy with increase of ISI occurred between the 1.5-sec and 4-sec points (Fig. 2). Based on difference scores computed from the arcsin transform of proportion correct for each $S$, recognition accuracy was reliably greater at $1.5 \mathrm{sec}$ ISI than at $4 \mathrm{sec}$ ISI $[\mathrm{t}(23)=2.43$, $\mathrm{p}<.025$ ], yet not reliably greater at $4 \mathrm{sec}$ ISI than at $12 \mathrm{sec}$ ISI $[\mathrm{t}(23)=.92$, n.s. $]$. Recognition performance at 12 and $20 \mathrm{sec}$ were virtually identical, and $t$ tests indicated reliable differences of performance from a chance level $(0.5)[t(23)=5.48$ and $5.97, p<.001]$ for $12-$ and 20 -sec ISI, respectively.

The above-chance recognition performance indicates that enough detailed information about a figure was retained for at least $20 \mathrm{sec}$ to permit a discrimination of very similar figures. The implication is that, because of the nature of the figures used in the study, it is highly unlikely that recognition was based on a purely verbal coding of the figures. The difference between the figures in each different pair was unique and not characterized by any obvious dimension that would serve to differentiate any other pair of figures. Thus, it would not be possible, given any figure in the presentation sequence, to know how the upcoming test figure would differ from it, if at all. Also, the differences between figures in the different pairs were small. Because of (1) the uncertainty as to which details would be important for the upcoming test, and (2) the fineness of the discrimination to be made, it would be necessary to remember much complex detailed information to perform the task. This information had to be internalized during $5 \mathrm{sec}$ presentation time (plus whatever time an "icon" might have been present). If the target figure were coded purely verbally and the verbal code was what persisted during the ISI to be used in the recognition task, then this verbal code would necessarily have been very detailed, perhaps a long description or set of terms describing a finely discriminative feature list. It seems unlikely that such a verbal coding of one of these figures could have been generated in the 5 -sec presentation interval or even during the longest retention interval.

Although the nature of the present task makes implausible any account of the data in terms of a purely verbal code of the stimuli, it is still quite possible that some sort of coding, a bstraction, or other information-reducing process was applied to the figures to be recognized. Evans (1967) and Posner (1969), for example, explicitly proposed that visual information is coded in abstract or schematic form. If such a recoding were taking place in the present experiment, the decrease in performance from delays of 1.5 to $4 \mathrm{sec}$ (Fig. 2) suggests that such recoding is essentially complete by 4 sec after stimulus offset, even for complicated figures such as those used here. Also, verbal reports from Ss indicate that any possible abstraction process was not voluntary or conscious in this case.

The nearly asymptotic recognition performance at well above chance around $20 \mathrm{sec}$ delay (Fig. 2) suggests that performance would also be above chance at substantially greater delays. It thus appears that nonverbal representations of visual information can be remembered for periods spanning what is often thought of as the extent of short-term memory.

\section{REFERENCES}

ATKINSON, R. C., \& SHIFFRIN, R. M. Human memory: A proposed system and its control processes. In K. W. Spence and J. T. Spence (Eds.), Psychology of learning and motivation: Advances in research and theory. Vol. 2. New York: Academic Press, 1968.

EVANS, S. H. A brief statement of schema theory. Psychonomic Science, 1967, 8, 87-88.

HEIDER, E. R., \& OLIVIER, D. C. The structure of the color space in naming and memory for two languages. Cognitive Psychology, in press. 
KROLL. N. E. A. PARKS. T. PARKINSON, S. R BIEBER S. L \& JOHNSON. A. L. Short-term memory while shadowing: Recall of visually and of aurally presented letters. Journal of Experimental Psychology, 1970, 85, $220-224$

SORMAN. D. A. Memory and attention. New York: Wiley, 1969.

PHILLIPS. W. A.. \& BADDELEY. A. D. Reaction time and short-term bisua memory. Psrchonomic Science, 1971, 22. $73-74$.
POSNER .1. I Abstraction and the process of recognirion. In $J, T$. Spence and $G$. Bower (Eds.). Psychology of learning and motiution: Aduances in research and theory. Vol. 3. New York: Academic Press. 1969

POSNER, H. I., \& KONICK, A. F. Shorteterm retention of visual and kinesthetic information. Organizational Behavior \& Human Performance, 1966, 1 , 71-86.
NOTE

1. Each figure has a unique pair of parameters associated with it. "Adjacent" refers to two figures being one parameter step from each other along one of the two parameter dimensions in the parameter space of the figures. The parameter dimension used to define adjacency was the "horizontal" dimension referred to in Shepard \& Cermak (in press).

2. Shepard, R. N., \& Cermak, G. W. A psychologically calibrated toroidal set of free-form stimuli. In preparation.

\section{CURRENT LITERATURE ON HUMAN MENORY}

AARONSON, D. (New York University, New York, N.Y. 10003), MARKOWITZ, N., \& SHAPIRO, H. Perception and immediate recall of normal and "compressed" auditory sequences. Perception \& Psychophysics, 1971, 9,338-344.

DICK, A. O. (University of Rochester, Rochester, N.Y. 14627). Processing time for naming and categorization of letters and numbers. Perception \& Psychophysics, 1971, 9, 350-352.

DOOST, R., \& TURVEY, M. T. (University of Connecticut, Stoors, Conn. 06268). Iconic memory and central processing capacity. Perception \& Psychophysics, 1971, 9, 269-274.

FOSS, D. J. (University of Texas at Austin, Austin, Tex. 78712), \& DOWELL, B. E. High-speed memory retrieval with auditorily presented stimuli. Perception \& Psychophysics, 1971, 9, 465-468.
GOLDSTEIN, A. G. (University of Missouri, Columbia, Mo. 65201), \& CHANCE, J. E. Visual recognition memory for comple $x$ configurations. Perception \& Psychophysics, 1971, 9, 237-241.

GORDON, I. E. (University of Exeter, Exeter, England), \& FENOULHET, $P$. Repeated vs varied distractors in immediate memory. Perception \& Psychophysics, 1971, 9, 474-476.

JUOLA, J. F. (Stanford University, Stanford, Calif. 94305 ), FISCHLER, I., WOOD, C.T., \& ATKINSON, R. C. Recognition time for information stored in long-term memory. Perception \& Psychophysics, 1971, 10, 8-14.

KEELY, K. (University of Western Australia, Nedlands, Western Australia, Australia). Age and task effects in short-term memory of children. Perception \& Psychophysics, 1971, 9, 480-482.
MARTIN, E. (Human Performance Center, University of Michigan, Ann Arbor, Mich. 48104). Verbal learning theory and independent retrieval phenomena. Psychological Review, 1971, 78, 314-332.

POSTMAN, L. (Institute of Human Learning, University of California, Berkeley, Calif. 94720). Organization and interference. Psychological Review, 1971, 78, 290-302.

TOWNSEND, J. T. (Purdue University, West Lafayette, Ind. 47907). Alphabetic confusion: A test of models for individuals. Perception \& Psychophysics, 1971, 9, 449-454.

WOLFORD, G. (Dartmouth College, Hanover, N.H. 03755). Function of distinct associations for pairedassociate performance. Psychological Review, 1971, 78, 303-313. 